\title{
Predictors and outcomes of speech and language therapists' treatment decisions
}

\section{SUE ROULSTONE, ${ }^{1}$ TIM J. PETERS,${ }^{2}$ MARGARET GLOGOWSKA,${ }^{1}$ and PAM ENDERBY ${ }^{3}$}

1. University of the West of England, Bristol, UK

2. University of Bristol, Bristol, $U K$

3. University of Sheffield, Sheffield, UK

Correspondence: Sue Roulstone, PhD, Professor of Speech \& Language Therapy, Speech \& Language Therapy Research Unit, Frenchay Hospital, Bristol BS16 1LE, UK. Tel: +44-1179186529. Fax: +44-117-9701119. Email: susan.roulstone@uwe.ac.uk

Running head: Speech and language therapists' treatment decisions 


\begin{abstract}
This study investigated predictors of decisions made by speech and language therapists (SLTs) to offer intervention for a pre-school child and the children's outcomes relative to that decision. The study uses data from 347 children who were first assessed aged under 3 years 6 months by community speech and language therapists in the UK. Of these, 158 were offered therapy, 189 were either discharged or offered only monitoring appointments. After adjusting for the child's age and gender, six variables were significantly associated with the therapist's original decision: being a quiet baby, not using two word utterances or making comments on their play, being unintelligible to strangers and the child's score on auditory comprehension and expressive language scales of the Preschool Language Scale. These show a focus on communication variables rather than broader demographic and medical variables. At follow-up, aged 7-9 years, $56 \%$ of the children were available for re-assessment. Therapists' decisions at initial assessment show a sensitivity of 0.85 and a specificity of 0.61 relative to children's outcomes. Of the 191 children seen at follow-up, 21 were deemed to have ongoing difficulties.
\end{abstract}

Keywords: treatment decisions, predictor variables, therapy, intervention, outcomes 
As clinicians delivering speech and language therapy (SLT) services we are under enormous pressure to make best use of our resources. The early decisions we make about whether or not to offer intervention at all are the first stage in a stream of decisions and arguably one of the most important we will make, since it is the point at which we control families' access to services. This paper reports a study whose purpose is to understand more about how those decisions are made, which factors seem to be influential and importantly, what the outcomes are for children we decide not to take-on for intervention.

One of the reasons that it is important to understand more about how we make these decisions is because of the variability that exists in practice. In the UK the phenomenon has been labelled "the postcode lottery". The variability in provision is documented in the literature. Enderby and John (1999), using the Therapy Outcome Measures, analysed the severity levels associated with acceptance onto and discharge from caseloads in 11 different health care Trusts in the UK. Their data suggest that to get access to therapy in some Trusts you have to have a more severe problem, while in some Trusts you will be discharged earlier in the course of your disorder. Some of this variability may well be related to the nature of the facility (e.g., acute vs. community) but the authors conclude that not all the variability can be explained by such differences in facilities.

There is also evidence of our variability as individual professionals. Records and Tomblin (1994) asked 27 therapists to analyse a series of case profiles, some unique and others duplicated. Overall the therapists showed a significantly better than chance agreement with each other about their diagnostic decisions. However, the study also showed variation between therapists. For example, at the extremes, one rater identified $89 \%$ of the cases as language impaired whereas 
another rater identified only $20 \%$ as language impaired. In a mixed method investigation of therapists' selection of preschool children for speech and language therapy, Roulstone (2001) identified sources of agreement and disagreement between therapists. They agreed about the categories or variables they investigated as they assessed a child and about the interpretation of the nature of the child's problems; there was also significant agreement about the relative priority of ten case profiles assessed by therapists. However, the approaches therapists took to conducting the assessments varied, as did the cut-off point at which they would actually offer intervention.

The decision to select children for intervention is particularly challenging for two further reasons: the relative dearth of literature regarding outcomes for children with early language delay and related intervention approaches and the absence of a definitive set of predictors. Law, Garrett and Nye (2003), in their systematic review of interventions, have concluded that there is evidence to support therapy for children with expressive phonological and expressive vocabulary impairment but less evidence for children with other or more mixed impairments. They further conclude that the evidence to help determine the most optimum timing of intervention (early versus later for example) is also lacking. Nippold and Schwarz (2002) argue strongly for intensive intervention for children diagnosed with specific language impairment; in the context of late talkers, seen before the age of 3 years, other writers advise a more cautious wait and see approach (Paul, 1996). Olswang, Rodrigues and Timler (1998) review the literature on the topic and present a wide range of risk and predictive factors, twenty seven in all, including speech and language features, characteristics of play, gesture and social skills, the presence of otitis media, family history as well as socio-economic factors and parenting style. Cummins and Hulme (2001, p. 55), on the other hand, focus on features of the child's speech and language identified in the literature 
such as communicative intent, poor pragmatic skills and on the prevention of negative interaction patterns. However, as Ellis Weismer (2000) concludes, there is as yet no clear set of indicators that allows us to predict which children will outgrow early speech and language delays, or indeed which children require intervention to benefit. A number of longitudinal studies of children have investigated predictors of longer term outcomes and these have tended to focus on the different outcomes for various diagnostic categories of speech and language difficulties; for example, differentiating between specific and non-specific language impairments (Stothard, Snowling, Bishop, Chipchase \& Kaplan, 1998) or between resolving and persistent delay. In the 18 month follow-up of children identified as language disordered at aged 4 years, Bishop and Edmundson (1987) concluded that those with milder impairments and with fewer affected linguistic domains generally made better progress over the 18 month period. Stothard et al. (1998) in the later follow-up of these children, similarly focus on the nature of the children's deficits, whether specific language impairment or a more general delay. Those children who had apparently resolved their earlier difficulties by the age of 5;6 years, still performed significantly lower on tests of nonword repetition and spoonerism than did control children; those who had impaired speech and language difficulties and those with a more general delay did not differ significantly from each other except on measures of their nonverbal performance. In their long term follow-up of children seen first when they were 5 years of age with speech and language impairment, Johnson et al. (1999) noted better outcomes for those children with speech impairment and with specific language impairments compared to language impairments which were secondary to neurological, cognitive, sensory or structural deficits. 
For therapists assessing children on a daily basis, the problem is one of interpreting and applying such findings with respect to the individual child. Emanuel, Chiat and Roy (2007), tracking the outcomes of a decisions made by a single speech and language therapist (SLT), found a significant relationship between the diagnostic and prognostic decisions of the therapist and the decisions taken at initial assessment and also the severity at follow-up. However, approximately three-quarters of children given a mild rating by the therapist were offered intervention (although the amount of intervention given is not specified). The authors note the complex relationship between the severity of the impairment and the decision to intervene.

The decision making of SLTs as they assess whether or not a child should be offered intervention is a complex and uncertain process and one where the research evidence is inconclusive. A study of children referred to speech and language therapy during their pre-school years and followed up whilst they were in junior school provides an opportunity to investigate the decisions made by therapists (Glogowska, Roulstone, Peters \& Enderby, 2006). When the children were first referred and assessed, SLTs made decisions about whether or not the children presented with clinically significant difficulties. At follow-up, there were statistically significant differences between those who were originally perceived to have clinically significant difficulties and those who were not so perceived (Glogowska et al., 2006). The purpose of this paper is firstly to investigate which variables are associated with the therapist's initial decision. It may be that the everyday clinical experience of SLTs can shed light on which variables might be considered to guide clinical decisions and potentially be useful for future investigations. A second and related aim is to investigate the children's long-term outcomes relative to that original SLT decision, particularly for those children who are not offered intervention. The study methods and results 
are presented in two parts - the baseline study and the follow-up study, then brought together in the discussion and conclusions.

\section{The Baseline Study}

\section{Participants}

The baseline sample is derived from children assessed as part of recruitment to a pragmatic randomized controlled trial (RCT) to compare routine speech and language therapy for preschool children with delayed speech and language, with a 12 month period of monitoring (Glogowska, Roulstone, Enderby \& Peters, 2000). In preparing for the recruitment of children, the RCT was discussed with SLT managers and staff of children's SLT services in the Bristol area of the UK. Two Trusts (of the six approached) volunteered to take part. Within the two Trusts, together with the SLT managers, we identified 16 community clinics with 21 SLTs who were at least one year post-qualification and where the majority of the children referred were from an English speaking background. Clinics receiving tertiary referrals were excluded. The included clinics were all based in community health centers and clinics receiving referrals directly from the community via health visitors, parents, general practitioners and nursery staff.

During the period of recruitment to the RCT, 507 children, referred successively to these clinics were assessed by the local SLT. Children were included in the baseline study if they were under 3 years and 6 months of age, if parents consented to the initial assessments and to their data being kept for follow-up purposes $(n=354)$. Children were excluded $(n=153)$ if they had severe learning difficulties or other pervasive developmental conditions, fluency, voice or oromotor speech impairments, came from non-English speaking home backgrounds, were twins or had other siblings in the study. 


\section{Assessments}

At baseline, children were assessed using the Pre-School Language Scales (PLS-3) (Zimmerman, Steiner \& Pond, 1992) and a single word phonological analysis of 22 words yielding a percentage error rate (adapted from Pagel Paden, Novak \& Beiter, 1987). Information was also collected about the child's medical and developmental history. These data were collected by the child's local clinician. Baseline assessments were originally selected for the purposes of stratifying the RCT sample on the basis of their expressive and receptive language and their phonology. Since the children were under 3 years and 6 months of age and the assessments took place in everyday clinical contexts, it was also important that the assessment process was not too lengthy, thus restricting the number of assessments that could be used.

\section{Group allocation}

Following the baseline assessments and prior to inclusion and randomisation within the RCT, SLTs were required to make explicit their decisions regarding their management of the child. This decision forms the basis of the analysis in this baseline study. Therapists were not guided in this decision but asked to record their normal decision. Analysis of these decisions showed four broad categories (see Figure 1): a) discharged: SLTs indicated that no problems were detected and the child was considered to be within normal limits $(n=26)$; a further 55 children were also discharged, but in these instances SLTs indicated that they had given advice to the families to support ongoing development of the children suggesting the possible presence of negative indicators; b) other referrals $(n=3)$ : a small number of children were referred on to other agencies such as clinical psychology and for hearing assessment; the SLTs did not plan to see these 
children again; c) monitored ( $\mathrm{n}=108)$ : in these children, SLTs indicated that they wished to monitor or review the children's progress at some point in the future (for example 3-6 months time); d) therapy ( $\mathrm{n}=162)^{1}$ : SLTs indicated that there was a clinically significant difficulty; four of these children subsequently withdrew from the study. For the purposes of analysing predictors of the therapists' decisions, we have contrasted those children who were perceived to warrant intervention ( $n=158)$ with those who were discharged or merely monitored $(n=189)$ (Figure 1). Children who were referred to another discipline were excluded from the analysis $(n=3)$.

\section{Insert figure 1 about here}

\section{Predictor variables}

In the baseline study, SLTs used a standard questionnaire, devised for the RCT, to collect medical, demographic and developmental case history information about the child and family. Parents filled this in independently in most cases but whilst they were with SLT, thus help was available where needed if parents had queries or difficulties completing items. Despite this, not all parents answered all the questions and there are missing data (see Table 1). We were particularly interested to investigate variables that seem to be associated with the therapists' decisions rather than examining variables from the literature that predict the longer-term outcomes. Therefore, in order to identify relevant variables for the analysis, we referred to a qualitative investigation of therapists' decision making (Roulstone, 1997) which provides a model of the factors considered by SLTs as they select preschool children for therapy. The model, henceforth called the Roulstone model, derived from data collected through interviews, observation and focus groups with SLTs, suggests that SLTs consider both the child's difficulties and the child's context; that children's presenting communication difficulties will take

\footnotetext{
${ }^{1} 159$ of these children were recruited to the RCT.
} 
precedence over other presenting features and their communication history will be of more significance than other features of their history.

As this was a post-hoc analysis of the data, rather than a planned investigation of SLTs decisionmaking, it was not possible to construct the analysis in a way that investigates the Roulstone model systematically. However, it was felt that the model provided a structured and reasoned method of selecting and grouping variables from the case history data. Using the Roulstone model, variables were identified from the case history and assessment data collected by therapists at baseline to represent as many of the factors described in the model as possible. Table 2 shows how these were grouped to follow the model proposed in Roulstone (1997). A number of more general demographic factors, such as mother's age and education, that had not been explicitly mentioned in the Roulstone model, were also added (see Table 2). These were all converted into binary variables. For example, in the case history questionnaire parents were asked to indicate their level of education and training from a choice of five alternatives. For the analysis, this was converted into a binary variable of "education up to 16 years of age" in contrast with "education beyond 16 years of age". Table 1 shows the descriptive data for each binary variable for the two groups, Therapy and Discharged.

\section{Insert tables $1 \& 2$ about here}

\section{Analysis}

This process generated a list of 32 factors for analysis from which we generated 32 binary explanatory variables. Using the therapist's decision as the outcome variable, each explanatory variable was entered into a logistic regression analysis individually, using SPSS (version 14.0, 2005). Also included at this stage were the child's age, gender, and performance on baseline 
assessments - PLS auditory comprehension and expressive language and the phonology error rate. Any factors that were statistically significant beyond a liberal threshold of 0.1 were taken forward to the next stage of analysis. Statistically significant variables were then considered in groups following the model described above (see Table 2). Following this stage, any variables that were still statistically significant at the 0.1 level were then taken forward to a final analysis. All remaining variables were entered into the model and then eliminated one at a time where statistical significance did not reach 0.05 .

\section{Results}

Figure 1 provides participant flow information. Of the 507 children assessed, 239 ( 77 who were excluded and 162 included) were seen as a priority for intervention. Table 3 provides descriptive results for the 347 included children at baseline, in terms of whether they were offered intervention $(\mathrm{n}=158)$ or were not $(\mathrm{n}=189)$. The results show considerable heterogeneity within each group and wide overlap between the two groups, although the differences between the groups are statistically significant $(\mathrm{p}<0.05)$ on all characteristics and measures except the phonology error score.

\section{Insert table 3 about here}

Table 1 compares the two groups on each of the 32 variables considered in the analysis. Table 4 shows the predictor variables that remained statistically significant at the end of the analyses. These variables were all statistically significant at better than the 0.1 level both in the univariable analyses and in the first phase modelling. Adjusting for the child's gender and age at baseline, six variables are associated with an increase in the odds of being assigned to intervention: being a quiet baby, using less than two word utterances, not providing comments on own play, being unintelligible to strangers and the child's standard scores on the auditory comprehension and 
expressive scales of the PLS-3. The odds of getting therapy increased by approximately three times if the child was reported as a quiet baby, was not using two word utterances, was not providing comments on play and was unintelligible to strangers; as the scores on auditory comprehension and expressive language increased, the odds of getting therapy decrease.

\section{Insert table 4 about here}

\section{The follow-up study}

\section{Procedure}

Children from the baseline study $(n=347)$ were invited for a follow-up assessment when they were in junior school, aged between 7 and 9 years. At follow-up, the children were seen mostly in school and all parents were invited to be present. The measures selected were designed to cover a broad range of speech and language skills. Given the heterogeneity of the baseline sample, it was important to cover a range of skills in order to investigate the breadth of likely outcomes. The following measures were used: British Picture Vocabulary Scale II (BPVS II) (Dunn, Whetton \& Pintil, 1997); Test for Reception of Grammar (TROG) (Bishop 1986); Test of Language Competence (TLC) (Wiig \& Secord 1988); Goldman-Fristoe Test of Articulation-2 (GFTA-2) (Goldman \& Fristoe 2000); Clinical Evaluation of Language Fundamentals-3 (CELF-3) (Semel, Wiig \& Secord, 2000) (recalling sentences subtest). Assessments were conducted by research clinicians who were blind to any group allocation or intervention received. At follow-up, current SLT records were cross-referenced to discover which children were currently receiving therapy.

\section{Defining children's outcomes}

In the literature, a number of different methods are used to define outcomes in children with language impairments. For example, Conti Ramsden, Botting, Simkin and Knox (2001) define 
resolution in their sample as any child who has no scores $<16^{\text {th }}$ centile. Bishop and Edmundson (1987) identify a child as resolved if they have no scores <2SD below the mean and no more than one score $<1 \mathrm{SD}$ below the mean. Selecting any particular definition can be a relatively arbitrary process. For the purposes of this paper, it was decided that an average score across the six assessments would be used, with a cut-off point that was validated against parent and teacher perspectives of the child. To enable scores to be combined in the calculation of the average score, because of the variation in the standardisations, it was necessary to calculate the child's $\mathrm{z}$ score for each assessment individually. A process similar to that used by Tomblin, Records and Zhang, (1996) was then used to determine the cut-off point. In this case, the sensitivity and specificity of a number of cut-off points ( $\mathrm{z}$ scores between -1.0 and -2.0 ) were tested against parent and teacher views at follow-up. Parents and teachers were asked to indicate whether or not a child had an ongoing problem. The -1.25 cut-off yielded the best balance of sensitivity (0.85) and specificity (0.81). This suggests that $85 \%$ of those identified by parents and teachers as having an ongoing problem would be correctly identified by the -1.25 cut-off point and $81 \%$ of those who were not viewed as cases by parents and teachers would be correctly identified by this cut-off.

\section{Results}

At follow-up, data were available for 191 children on the outcome measures, 108 from the discharged group (57\%) and 83 from the therapy group (52\%). There were no statistically significant differences in the ratio of boys:girls or in the baseline scores of those lost to follow-up compared to those available. Table 5 shows the descriptive results for the assessments at followup for the two groups, showing considerable overlap between the two groups. Of those 191 children, 21 had an average $\mathrm{z}$ score on the speech and language assessments of less than -1.25 
$\mathrm{SD}$. Of the 83 children in the therapy group, 18 had an average $\mathrm{z}$ score of less than -1.25 ; of the 108 in the discharged group, only 3 scored below -1.25 Using a sensitivity and specificity analysis and the children's speech and language outcome as a reference against which to evaluate the therapists' baseline decision, the sensitivity of the therapists' decision is 0.85 and the specificity is 0.61 . That is, the original SLT decision correctly predicts $85 \%$ of the children whose average $\mathrm{z}$ score is below -1.25 at follow-up and $61 \%$ of those who have an average score above -1.25 . Of those children who were originally discharged or monitored, 6 were now on therapy lists and 21 of those originally allocated to therapy were still accessing therapy.

\section{Insert table 5 about here}

\section{Discussion}

For the purposes of this study, the numbers of children referred but not allocated to therapy as part of the recruitment to a RCT allowed a post-hoc investigation of the SLT decision whether or not to offer intervention. However, as a post-hoc analysis, this means that the assessments and variables chosen for analysis were not originally designed for this particular analysis. Nevertheless, the analyses provide useful insights into the variables associated with the therapists' decisions and into the outcomes of the children relative to those decisions.

In terms of the variables predicting the clinician decision, 6 of the 32 remained statistically significant when the relationships between the variables were taken into account. Those variables are all descriptions of the child's communication skills and apart from one (reported as being a quiet baby) describe the child's current communication skills at the time of the assessment. That is, the broader developmental, medical and demographic variables did not remain in the final model. Similarly, in the analysis of variables considered by therapists, Roulstone (1995) found 
that, the stronger the link to communication, the more frequently a variable was cited as important (p. 142). Whilst this may not be surprising to SLTs, it raises interesting questions in terms of the roles of other variables in our case history investigations. Therapists in Roulstone's study reported that the broader factors, such as family history were often difficult to interpret in terms of their significance for an individual case (p.151). This possibly reflects the paucity of the literature for example, where the probability of having a speech and language impairment cannot yet be predicted from any particular variable either alone or in combination. If the predictive value of other variables is so unclear, it could be suggested that therapists should focus on the communication variables alone. Indeed it has been suggested that in some decision domains, where there is high redundancy of data, it would be better for professionals to reduce the complexity and cognitive load of their decision making by reducing the number of variables they consider (Elstein \& Bordage, 1988). Perhaps instead we should focus on those where there is a known probability of outcome. It might therefore seem to be a reasonable argument to narrow our case history taking, focusing in more detail on the communication aspects of a child's history and presentation. However, the Royal College of Speech and Language Therapists' Clinical Guidelines (RCSLT, 2005) recommends that an initial case history should include the broader range of variables including medical, social, environmental factors as well as communication issues, whilst acknowledging that "some may not be applicable for every individual" (RCSLT, 2005, p. 13). Typically clinicians do not routinely ask all the questions of a traditional case history format unless they are taking part in a research study that requires them to do so. More frequently, they use hypothesis testing approaches (Parker \& Kersner, 2001, p. 15), whereby initial clues from a family's story are used to induce hypotheses about the nature of a child's 
problem, which are then investigated in turn, to be either rejected or confirmed by subsequent evidence.

The broader variables such as family history or perinatal history, feeding history and developmental milestones are likely to be important in understanding the nature, origins and likely prognosis for any individual child. However, for this group of preschool children, being assessed in UK community clinics, these broader features did not significantly affect the odds of getting access to intervention. That is, clinicians maybe using a broader set of information to help them understand the nature of a child's difficulties but only a small percentage of these will actually impact on that decision to intervene or not. The other factors may be important in determining which aspects of a child's communication were assessed or the content of subsequent therapy. It is important to bear in mind at this point that the full range of variables described in the Roulstone model (Roulstone, 1997) was not available in this data set. For example, we did not collect data about the child's general developmental functioning.

It would be inappropriate to assume that the variables associated with therapists' decisions are also associated with outcome even though the therapists' decisions are significantly associated with the children's outcome (Glogowska et al., 2006) and this study does not address the prediction of outcome from the baseline variables. However, the study was designed to investigate the outcomes for children who were not offered intervention at baseline. The descriptive outcomes for these children show considerable variation and overlap between groups. Despite this and the dearth of literature regarding the outcome of early speech and language delay, clinicians in this study had a reasonably high level of accuracy in predicting case children, 
with $85 \%$ being identified. Only three children who later presented as having an ongoing problem were not offered therapy at baseline, although we cannot tell from our analysis whether there is variation between therapists in their ability to predict these outcomes. It is difficult to interpret the specificity figure of 0.61 which means that nearly $40 \%$ of children of the children whose problems appeared to have resolved at follow-up were identified as case children at initial assessment. From this, it might be argued that therapists tend to over-identify children who go on to resolve their problems over time. Of course, we cannot judge what might have been the outcome had intervention not been offered and, given the evidence regarding the negative outcomes for children with ongoing problems (Johnson et al., 1999; Stothard et al., 1996), it would be risky to tighten the criteria without further evidence about the natural history of early language impairment.

Neither is it possible to know how the views of families influenced SLTs' decisions. Roulstone's (1997) qualitative study of therapists' decisions showed that SLTs do take account of families' attitudes and their level and focus of concern and it is accepted good practice to involve families in the decision making process. As noted above, Emanuel et al. (2007) report that over $76 \%$ of children who were rated as having a mild problem at initial assessment were offered therapy, suggesting that factors other than the severity of the child's problem influence therapists' decision to offer therapy. Families' views about the potential impact and value of therapy are clearly crucial, but perhaps not always as we would expect. For example, Glogowska and Campbell (2000) investigated the perspectives of families involved in the RCT and reported that although most were eager to access therapy, this was not the case for all parents: for some parents, providing their child continued to make progress, a period of monitoring was regarded as a positive strategy. 


\section{Conclusion}

In this study SLTs selected children for therapy who seemed least likely to resolve and conversely discharged or monitored those that were more likely to resolve: they seemed to be making the right decisions. However, they also selected for intervention a number of children as preschoolers who were apparently within normal limits at follow-up. This suggests that there is room for investigating this aspect of practice further, particularly in terms of families' views of the value and impact of services and what aspects of the service was valued.

Although broader factors are linked to therapists' decisions, when considered together, and when age and gender are taken into account, statistical models that include the child's communication at baseline are the better predictors of the therapists' decision, perhaps reflecting both the nature of the children's difficulties and the expertise of the profession. One of the imperatives driving this work was recognition of the variation that exists within the profession and a desire to better understand the decisions that lead to this variation. By reflecting on and analysing our decisions, we can begin to understand how far the variation matters and what adjustments could be made to standardise practice.

\section{Acknowledgements}

Our thanks go to the parents and children who participated in the study and who helped with the training of therapists on the study, to Kate Francis and Elizabeth Elford, members of the research team, to all the speech and language therapists working in the Bristol area who participated in these studies, and to our funding agency, the National Health service SouthWest Research \& Development Programme. 


\section{References}

Bishop, D. V. M. (1986). Test for Reception of Grammar. Manchester: University of Manchester, The Age and Cognitive Performance Research Centre.

Bishop, D. V. M., \& Edmundson, A. (1987). Language impaired 4-year olds: Distinguishing transient from persistent impairment. Journal of Speech and Hearing Disorders, 52, 156-173. Conti-Ramsden, G., Botting, N., Simkin, Z. \& Knox, E. (2001). Follow-up of children attending infant language units: Outcomes at 11 years of age. International Journal of Language and Communication Disorders, 36(2), 207-219.

Cummins, K. \& Hulme, S. (2001). Managing pre-school children in community clinics. In M.Kersner \& J. A.Wright (Eds.), Speech and language therapy: The decision-making process when working with young children (pp. 53-62). London: David Fulton Publishers.

Dunn, L., Whetton, C., \& Pintil, D. (1997). British Picture Vocabulary Scales II. (2nd ed.). Windsor: NFER-Nelson.

Ellis Weismer, S. (2000). Intervention for children with developmental language delay. In D. V. M. Bishop \& L. B. Leonard (Eds.), Speech and language impairments in children (pp. 157-176). Hove: Psychology Press.

Elstein, A. \& Bordage, G. (1988). Psychology of clinical reasoning. In J. Dowie \& A. Elstein (Eds.), Professional judgement. A reader in clinical decision making (pp. 109-129). Cambridge: Cambridge University Press.

Emanuel, R., Chiat, S. \& Roy, P. (2007). Evaluation of the clinical decisions made for 2-yearolds referred for speech and language therapy: A follow-up study. International Journal of Language and Communication Disorders, 42(S1), 1-15. 
Enderby, P., \& John, A. (1999). Therapy outcome measures in speech and language therapy: Comparing performance between providers. International Journal of Language and Communication Disorders, 34(4), 417-429.

Glogowska, M. \& Campbell, R. (2000). Investigating parental views of involvement in preschool speech and language therapy. International Journal of Language and Communication Disorders, 35(3), 391-405.

Glogowska, M., Roulstone, S., Peters, T. J., \& Enderby, P. (2006). Early speech and language impaired children: Linguistic, literacy and social outcomes. Developmental Medicine and Child Neurology, 48, 489-494

Glogowska, M., Roulstone, S., Peters, T. J., \& Enderby, P. (2000). Randomised controlled trial of community-based speech and language therapy for pre-school children. British Medical Journal, 321, 923-926.

Goldman, R., \& Fristoe, M. (2000). Goldman-Fristoe Test of Articulation 2. Circle Pines, MN: American Guidance Services.

Johnson, C. J., Beitchman, J. H., Young, A., Escobar, M., Atkinson, L., Wilson, B., Brownlie, E. B., Douglas, L., Taback, N., Lam, I. \& Wang, M., (1999). Fourteen-year follow-up of children with and without speech/language impairments: Speech/language stability and outcomes. Journal of Speech, Language, and Hearing Research, 42, 744-760.

Law, J., Garrett, Z., \& Nye, C. (2003). Speech and language therapy interventions for children with primary speech and language delay or disorder (Cochrane Review). In The Cochrane Library, Issue 3. Oxford: Update Software.

Nippold, M. A. \& Schwarz, I. E. (2002). Do children recover from specific language impairment? Advances in Speech-Language Pathology, 4(1), 41-49. 
Olswang, L. B., Rodrigues, B., \& Timler, G. (1998). Recommending intervention for toddlers with specific language learning difficulties: We may not have all the answers, but we know a lot. American Journal of Speech-Language Pathology, 7, 23-32.

Pagel Paden, E., Novak, M. A., \& Beiter, A. L. (1987). Predictors of phonologic inadequacy in young children prone to otitis media. Journal of Speech and Hearing Disorders, 52, 232-42.

Parker, A., \& Kersner, M. (2001). Developing as a speech and language therapist. In M. Kersner \& J.A. Wright (Eds.), Speech and language therapy: The decision making process when working with children (pp. 12-29). London: David Fulton Publishers.

Paul, R. (1996). Clinical implications of the natural history of slow expressive language development. American Journal of Speech-Language Pathology, 5, 5-21.

Records, N. L., \& Tomblin, J. B., (1994). Clinical decision making: Describing the rules of practicing speech-language pathologists. Journal of Speech and Hearing Disorders, 37, 144-156. Roulstone, S. (1995). The child, the process and the expertise: Identification of priority children from preschool referrals to speech and language therapy. Unpublished $\mathrm{PhD}$ thesis, Brunel University.

Roulstone, S. (1997). What's driving you? A template which underpins the assessment of preschool children by speech and language therapists. European Journal of Disorders of Communication, 32, 299-315.

Roulstone, S. (2001). Consensus and variation between speech and language therapists in the assessment and selection of preschool children for intervention: A body of knowledge or idiosyncratic decisions? International Journal of Language and Communication Disorders, 36 (3), 329-348. 
RCSLT (2005). Royal College of Speech and Language Therapists Clinical Guidelines. Oxon: Speechmark Publishing.

Semel, E., Wiig, E. H., \& Secord, W. (2000). Clinical Evaluation of Language Fundamentals III (UK). San Antonio, TX: Psychological Corporation.

Stothard, S. E., Snowling, M. J., Bishop, D. V. M., Chipchase, B. B. \& Kaplan, C. A., (1998), Language-impaired preschoolers: A follow-up into adolescence, Journal of Speech and Hearing Research, 41, 407-418.

Tomblin, J. B., Records, N. L., \& Zhang, Z. (1996). A system for the diagnosis of specific language impairment in kindergarten children. Journal of Speech, Language, and Hearing Research, 39(6), 1284-1294.

Tversky, A., \& Kahneman, D. (2005). Judgement under uncertainty; heuristics and biases. In M. H. Bazerman (Ed.), Negotiation, decision making and conflict management, Vol 1-3 (pp. 251258). Cheltenham, UK: Edward Elgar Publishing.

Wiig, E. H., Secord, W. A. (1988). Test of Language Competence. San Antonio, TX: Psychological Corporation.

Zimmerman, I. L., Steiner, V. G., \& Pond, R. E. (1992). Preschool Language Scale - 3. San Antonio, TX: The Psychological Corporation. 
Table 1. Predictor variables

\begin{tabular}{|c|c|c|c|c|c|}
\hline Variable & $\mathrm{N \#}$ & & Discharged & Therapy & $\begin{array}{c}\mathrm{p} \text { value } \\
\text { Odds ratio(CI) }\end{array}$ \\
\hline Child's age at baseline & 347 & Mean in months & 33.9 & 32.9 & \\
\hline \multirow[t]{2}{*}{ *Sex } & \multirow[t]{2}{*}{347} & Male & 119 & 121 & \multirow{2}{*}{$\begin{array}{c}0.007 \\
1.9(0.33,0.83)\end{array}$} \\
\hline & & Female & 70 & 37 & \\
\hline \multirow[t]{2}{*}{ Mother's qualification } & \multirow[t]{2}{*}{303} & Up to GCSE** & 125 & 137 & \multirow{2}{*}{$\begin{array}{c}0.64 \\
1.9(0.27,1.04)\end{array}$} \\
\hline & & $\begin{array}{l}\text { Better than } \\
\text { GCSE }\end{array}$ & 26 & 15 & \\
\hline \multirow[t]{2}{*}{ Father's qualifications } & \multirow[t]{2}{*}{267} & Up to GCSE & 120 & 106 & \multirow{2}{*}{$\begin{array}{c}0.72 \\
1.1(0.96,3.7)\end{array}$} \\
\hline & & $\begin{array}{l}\text { Better than } \\
\text { GCSE }\end{array}$ & 23 & 18 & \\
\hline *Mother's age & 313 & Mean in months & 32.1 & 30.6 & $\begin{array}{c}0.004 \\
0.93(0.88,0.98)\end{array}$ \\
\hline \multirow[t]{2}{*}{ Problems during pregnancy } & \multirow[t]{2}{*}{308} & Yes & 28 & 23 & \multirow{2}{*}{$\begin{array}{c}0.51 \\
0.82(0.45,1.5)\end{array}$} \\
\hline & & No & 128 & 129 & \\
\hline \multirow[t]{2}{*}{ Problems during the child's birth } & \multirow[t]{2}{*}{308} & Yes & 28 & 33 & \multirow{2}{*}{$\begin{array}{c}0.44 \\
1.2(0.71,2.2)\end{array}$} \\
\hline & & No & 127 & 120 & \\
\hline \multirow{2}{*}{$\begin{array}{l}\text { Hospitalisation during child's life } \\
\text { to date }\end{array}$} & \multirow[t]{2}{*}{313} & Yes & 37 & 44 & \multirow{2}{*}{$\begin{array}{c}0.26 \\
1.3(0.81,2.2)\end{array}$} \\
\hline & & No & 123 & 109 & \\
\hline \multirow[t]{2}{*}{ Any medical problems } & \multirow[t]{2}{*}{310} & Yes & 46 & 40 & \multirow{2}{*}{$\begin{array}{c}0.54 \\
0.85(0.52,1.4) \\
\end{array}$} \\
\hline & & No & 111 & 113 & \\
\hline \multirow[t]{2}{*}{ Diagnosed hearing problems } & \multirow[t]{2}{*}{286} & Yes & 15 & 12 & 0.73 \\
\hline & & No & 135 & 124 & $0.87(0.39,1.9)$ \\
\hline *Family history of speech \& & 314 & Yes & 39 & 55 & 0.035 \\
\hline language impairment & & No & 120 & 100 & $1.7(1.04,2.76)$ \\
\hline *Feeding difficulties as a baby & 312 & Yes & 14 & 25 & 0.063 \\
\hline & & No & 142 & 131 & $1.9(0.96,3.9)$ \\
\hline Feeding difficulties as a child & 307 & Yes & 9 & 10 & 0.78 \\
\hline & & No & 146 & 142 & $1.1(0.45,2.9)$ \\
\hline Feeding difficulties at baseline & 306 & Yes & 9 & 11 & 0.56 \\
\hline & & No & 148 & 138 & $1.3(0.53,3.3)$ \\
\hline *Age of child's first words & 205 & $\begin{array}{l}\text { Mean age in } \\
\text { months }\end{array}$ & 19.1 & 20.8 & $\begin{array}{c}0.066 \\
1.0(0.99,1.09)\end{array}$ \\
\hline *Child was a quiet baby & 292 & Yes & 19 & 47 & $<0.001$ \\
\hline & & No & 126 & 100 & $3.1(1.72,5.6)$ \\
\hline Child was a difficult baby & 292 & Yes & 22 & 25 & 0.67 \\
\hline & & No & 123 & 122 & $1.1(0.61,2.1)$ \\
\hline *Child is currently babbling & 315 & Yes & 6 & 28 & $<0.001$ \\
\hline & & No & 154 & 127 & $5.7(2.5,8.3)$ \\
\hline *Child is currently using single & 315 & Yes & 18 & 57 & $<0.001$ \\
\hline words & & No & 142 & 98 & $4.6(2.5,8.3)$ \\
\hline *Child is currently using two- & 315 & Yes & 54 & 110 & $<0.001$ \\
\hline word utterances or better & & No & 106 & 45 & $4.8(2.9,7.7)$ \\
\hline *Child's current understanding & 315 & $\begin{array}{l}\text { Understands } \\
\text { some things }\end{array}$ & 18 & 54 & $\begin{array}{c}<0.001 \\
4.3(2.4,7.8)\end{array}$ \\
\hline & & $\begin{array}{l}\text { Understands } \\
\text { everything }\end{array}$ & 143 & 100 & \\
\hline Child initiates a conversation & 308 & Yes & 136 & 89 & $<0.001$ \\
\hline & & No & 22 & 61 & $4.2(2.4,7.4)$ \\
\hline Child answers an adult & 311 & Yes & 155 & 131 & 0.002 \\
\hline & & No & 5 & 20 & $4.7(1.7,12.9)$ \\
\hline Child commentates on own & 304 & Yes & 131 & 72 & $<0.001$ \\
\hline activity & & No & 26 & 75 & $5.2(3.1,8.9)$ \\
\hline
\end{tabular}




\begin{tabular}{|c|c|c|c|c|c|}
\hline \multirow{2}{*}{ Child talk to self whilst playing } & 306 & Yes & 146 & 118 & \multirow{2}{*}{$\begin{array}{c}0.004 \\
2.8(1.4,5.5)\end{array}$} \\
\hline & & No & 13 & 29 & \\
\hline \multirow[t]{2}{*}{ *Child is intelligible to family } & \multirow[t]{2}{*}{310} & Yes & 59 & 89 & \multirow{2}{*}{$\begin{array}{c}<0.001 \\
(1.5,3.7)\end{array}$} \\
\hline & & No & 99 & 63 & \\
\hline \multirow[t]{2}{*}{${ }^{*}$ Child is intelligible to strangers } & \multirow[t]{2}{*}{308} & Yes & 105 & 129 & \multirow{2}{*}{$\begin{array}{c}<0.001 \\
(1.7,5.1)\end{array}$} \\
\hline & & No & 52 & 22 & \\
\hline \multirow{2}{*}{$\begin{array}{l}\text { Child receives care outside the } \\
\text { family }\end{array}$} & \multirow[t]{2}{*}{315} & Yes & 98 & 87 & \multirow{2}{*}{$\begin{array}{c}0.29 \\
(0.50,1.2)\end{array}$} \\
\hline & & No & 61 & 69 & \\
\hline Amount of child care received & 313 & $\begin{array}{l}\text { Mean number of } \\
\text { half days }\end{array}$ & 2.0 & 1.8 & $\begin{array}{c}0.30 \\
(0.85,1.01 \\
\end{array}$ \\
\hline *Siblings in the family & 301 & Mean number & 1.2 & 1.4 & $\begin{array}{c}0.089 \\
(0.97,1.57)\end{array}$ \\
\hline *Auditory Comprehension & 326 & $\begin{array}{l}\text { Mean standard } \\
\text { score }\end{array}$ & 95.9 & 83.0 & $\begin{array}{c}<0.001 \\
0.94(0.93,0.96)\end{array}$ \\
\hline *Expressive language & 201 & $\begin{array}{l}\text { Mean standard } \\
\text { score }\end{array}$ & 46.2 & 49.7 & $\begin{array}{c}<0.001 \\
0.92(0.89,0.94)\end{array}$ \\
\hline Phonology & 201 & Mean error rate & 46.2 & 49.7 & $\begin{array}{c}0.411 \\
1.00(0.99,1.01)\end{array}$ \\
\hline
\end{tabular}

\# Not all parents $(\mathrm{n}=347)$ (usually mothers) answered all questions on the questionnaire, therefore the number responding to each item is variable.

* variables taken forward to multivariable analyses

**GCSE $=$ ???????? 
Table 2. Case history items compared with the Roulstone model

\begin{tabular}{|c|c|c|}
\hline General area & Roulstone model & Variable available \\
\hline General demography & & $\begin{array}{l}\text { Sex of child, mother and } \\
\text { father's education, mother's } \\
\text { age }\end{array}$ \\
\hline Other history & $\begin{array}{l}\text { suspect perinatal period, } \\
\text { potential relationship } \\
\text { difficulties, delayed } \\
\text { milestones, family history }\end{array}$ & $\begin{array}{l}\text { Pregnancy problems, birth } \\
\text { problems, feeding difficulties, } \\
\text { hospitalisation, additional } \\
\text { medical problems, hearing, } \\
\text { family history of speech/lang } \\
\text { problems, }\end{array}$ \\
\hline $\begin{array}{l}\text { Child's } \\
\text { communication } \\
\text { history } \\
\end{array}$ & $\begin{array}{l}\text { Delayed first words } \\
\text { Atypical early } \\
\text { communication }\end{array}$ & $\begin{array}{l}\text { Age of first words, quiet baby, } \\
\text { difficult baby }\end{array}$ \\
\hline $\begin{array}{l}\text { Child's current } \\
\text { communication }\end{array}$ & Comprehension, expression & $\begin{array}{l}\text { Parent's report on current stage } \\
\text { of language and intelligibility, } \\
\text { scores on Preschool Language } \\
\text { Scale }-3 \text { and phonology word } \\
\text { test }\end{array}$ \\
\hline Other behaviours & $\begin{array}{l}\text { Play, attention, social- } \\
\text { emotional }\end{array}$ & \\
\hline Child's context & $\begin{array}{l}\text { Interaction strategies and } \\
\text { attitudes of people in child's } \\
\text { context; provision of } \\
\text { resources (nursery, toys, } \\
\text { activities) }\end{array}$ & $\begin{array}{l}\text { Child care, number of days in } \\
\text { nursery, number of siblings }\end{array}$ \\
\hline
\end{tabular}


Table 3. Descriptions of the children at baseline

\begin{tabular}{|c|c|c|c|c|}
\hline Characteristic & $\mathrm{N}$ & Discharged & $\mathrm{N}$ & Therapy \\
\hline $\begin{array}{l}\text { Mean auditory } \\
\text { comprehension* } \\
\text { standard score } \\
\text { (range) } \\
\text { SD }\end{array}$ & 169 & $\begin{array}{l}95.9(64-134) \\
14.5\end{array}$ & 157 & $\begin{array}{l}83.0(53-127) \\
15.2\end{array}$ \\
\hline $\begin{array}{l}\text { Mean expressive } \\
\text { language* standard } \\
\text { score (range) } \\
\text { SD }\end{array}$ & 158 & $\begin{array}{l}89.1(67-135) \\
11.9\end{array}$ & 155 & $\begin{array}{l}77.4(53-135) \\
11.7\end{array}$ \\
\hline $\begin{array}{l}\text { Mean phonology } \\
\text { error rate** (range) } \\
\text { SD }\end{array}$ & 123 & $\begin{array}{l}46.2(0-100) \\
28.9\end{array}$ & 78 & $\begin{array}{l}49.7(0-100) \\
28.9\end{array}$ \\
\hline
\end{tabular}

*Preschool Language Scale -3

** word list adapted from Paden Pagel (1987) 
Table 4. Variables that are predictive of the therapist's baseline decision.

\begin{tabular}{|l|l|l|l|}
\hline Variable & $\begin{array}{l}\text { Odds Ratio } \\
(\mathrm{OR})\end{array}$ & $95 \%$ confidence interval for OR & $\mathrm{p}$ value \\
\hline Child age in months & 1.14 & $1.04,1.24$ & 0.004 \\
\hline Child's gender & 2.41 & $1.21,4.83$ & 0.013 \\
\hline Being a quiet baby & 3.28 & $1.49,7.16$ & 0.003 \\
\hline Using single word utterances & 3.54 & $1.39,8.95$ & 0.008 \\
\hline Not commenting on play & 2.79 & $1.27,6.18$ & 0.011 \\
\hline Unintelligible to family & 3.39 & $1.45,7.91$ & 0.005 \\
\hline Auditory comprehension standard score & 0.97 & $0.95,0.99$ & 0.018 \\
\hline Expressive language standard score & 0.95 & $0.91,0.98$ & 0.005 \\
\hline
\end{tabular}


Table 5. Descriptive results at follow-up

\begin{tabular}{|l|c|c|c|c|}
\hline $\begin{array}{l}\text { Language measure } \\
\text { Mean (range) }\end{array}$ & N & Discharged & N & Therapy \\
\hline $\begin{array}{l}\text { BPVS II } \\
\text { Standard score }\end{array}$ & 108 & $\begin{array}{c}100.6 \\
(71-128)\end{array}$ & 88 & $\begin{array}{c}92.8 \\
(64-122)\end{array}$ \\
\hline $\begin{array}{l}\text { TROG Standard } \\
\text { score }\end{array}$ & 108 & $\begin{array}{c}98.1 \\
(62-122)\end{array}$ & 89 & $\begin{array}{c}90.1 \\
(61-144)\end{array}$ \\
\hline $\begin{array}{l}\text { TLC } \\
\begin{array}{l}\text { Comprehension } \\
\text { Standard score }\end{array}\end{array}$ & $\begin{array}{c}9.2 \\
(4-14)\end{array}$ & 85 & $\begin{array}{c}8.1 \\
(3-16)\end{array}$ \\
\hline $\begin{array}{l}\text { TLC Expression } \\
\text { Standard score }\end{array}$ & 108 & 7.9 & 83 & 5.7 \\
\hline $\begin{array}{l}\text { GFTA-2 Standard } \\
\text { score }\end{array}$ & 108 & $\begin{array}{c}100.2 \\
(63-108)\end{array}$ & 87 & $\begin{array}{c}96.2 \\
(40-108)\end{array}$ \\
\hline $\begin{array}{l}\text { CELF Recalling } \\
\text { sentences subtest } \\
\text { Standard score }\end{array}$ & 108 & 7.6 & 88 & 5.7 \\
\hline
\end{tabular}


Figure 1. Participant flow chart

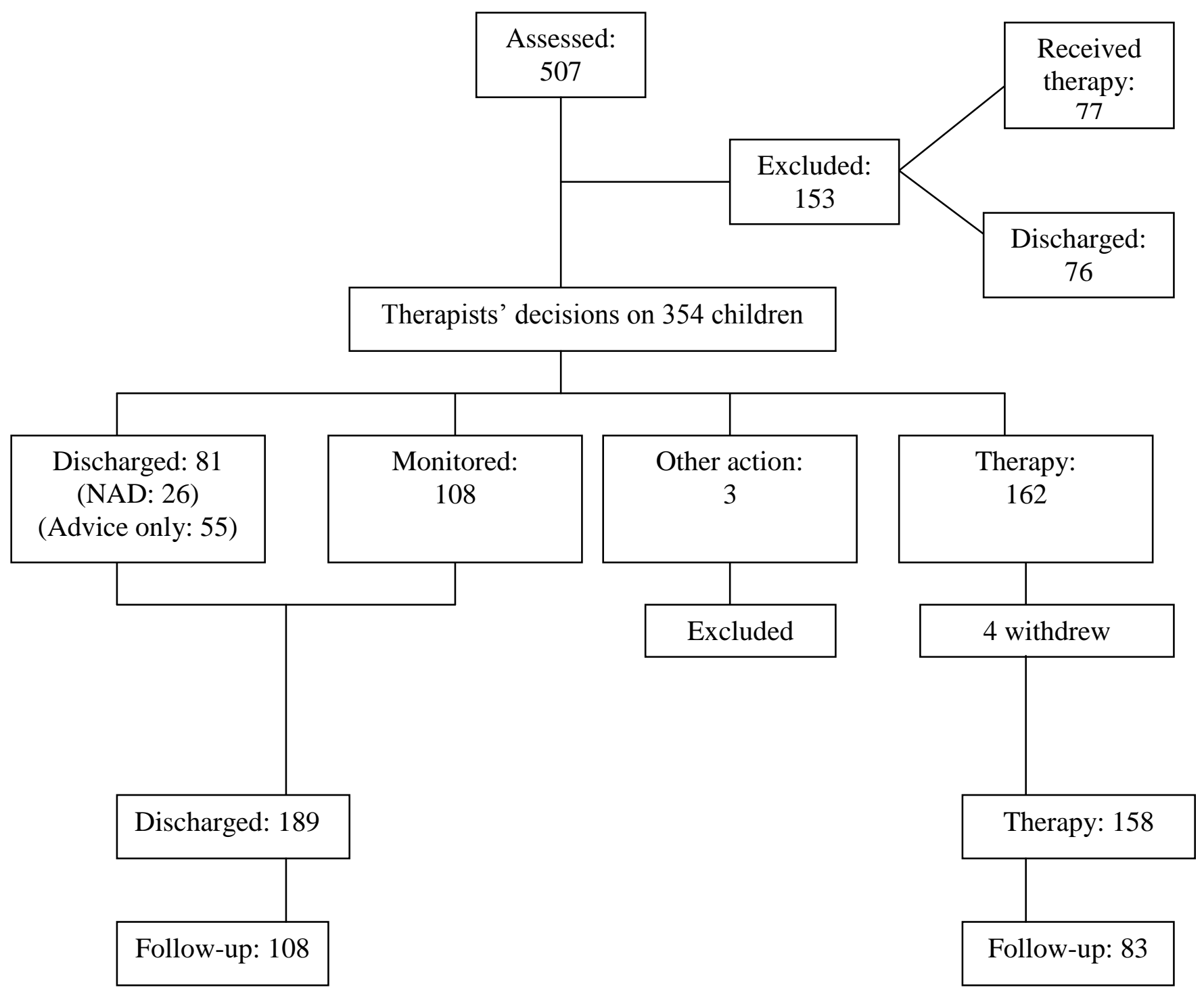

